\title{
The swirl of worlds: possession, porosity and embodiment
}

\author{
A boundary is not that at which something stops, \\ but as the Greeks recognized, the boundary is that from which \\ something begins its presencing. \\ Martin Heidegger
}

\section{Possession: mixing bodies and selves}

Janice Boddy, in her wide-ranging review of the scholarly literature on possession, begins with a concise definition:

Spirit possession commonly refers to the hold exerted over a human being by external forces or entities more powerful than she. These forces may be ancestors or divinities, ghosts of foreign origin, or entities both ontologically and ethnically alien [...] Possession, then is a broad term referring to an integration of spirit and matter, force or power and corporeal reality, in a cosmos where the boundaries between an individual and her environment are acknowledged to be permeable, flexibly drawn, or at least negotiable.

(Boddy 1994, 407)

But what exactly does it mean to say that 'the boundaries between an individual and her environment are acknowledged to be permeable'? Is it even conceivable as 'modern subjects' to know what this means not just in a theoretical sense but in real, experiential terms? Is it possible to understand rather than reduce and explain away possession within the ideological and discursive framework of modernity? - Modernity defined as a series of rejections, acts of distancing, and binary oppositions: mind-body, secular-religious, public-private, individualcommunity, nature-culture, rational-nonrational, Occident-Orient, and so on. ${ }^{1}$

What are the implications of Boddy's statement for our understanding of the 'I' that seemingly constitutes the core of a person? It could be argued that the dominant mode of experiencing self in the context of recent modernity is defined by the category of the individual who is an entity bounded above all by their body and mind. Moreover, the category of the individual marks off a self that is forged

1 Included in its many rejections is the notion of religion: 'of a sacramental view of reality and of anthropomorphic conceptions of the divinity, as well as even more radically [...] any notion of transcendence' (Benavides 1998, 190). 
out of an irreducible set of irreplicable circumstances. Individuals are both singular and unique, determining their destiny through the application of will that makes them active agents rather than passive on-lookers of the passage of their lives. The 'I' that simultaneously occupies as well as produces the category of the individual is constituted by thought. This shift in the notion of self occurs through the epistemic radicalism of Descartes whose thought is founded on the idea of profound doubt through which '[he] can affirm that he is not nothing because he is conscious of being something in and through the very act of consciousness itself' (Winquist 1998, 227). Thought causes the notion of 'I' to arise which then in turn views itself as a separate, bounded entity consisting of a body and mind with singular and unique thoughts and experiences. Within this framework, the thinking, conscious ' $I$ ' begins to occupy a place of primacy over being as 'the point of reference for the determination of meaning [...]' (ibid.). However, this dominant mode of identifying the question of self is radically challenged by the phenomenological enquiry of Heidegger that seeks to reinstate the ontological question of being as the fundamental question of philosophy. What does 'I' signify in the context of an enquiry into being rather than thinking? ${ }^{2}$ What would an understanding of possession mean in the latter context?

The following case study from the Central Himalayas will show that the 'I' and its corollaries of the person, of the individual, of singularity, and of agency cease to have primacy as points of reference. They seem to be on 'hold' or in suspension as other forces 'take over' and operate, as boundaries dissipate allowing for ever widening circles of divine or malevolent agency in which, as Becker notes, 'persons suddenly and inexplicably lose their normal set of memories, mental dispositions, and skills, and exhibit entirely new and different sets of memories, dispositions, and skills' (Smith 2011, 3). The acknowledgment of permeability between the individual and their environment has fundamental implications for self and its other. Clearly, an acknowledgement of permeability of 'flexibly drawn' boundaries implies that self and other are not simply oppositional, nor complementary, nor even relational. The relationship may involve all of these possibilities, and yet go beyond them to be identified through equivalence, enmeshing, continuity. It may involve a Moebius-like quality in which the inner and outer merge seamlessly, creating only a mirage-like impression of separate surfaces (Handelman, Shulman 2004, 44). On one level, the difference between self and other appears real, but on another level it may become illusory. Thus we require some other, radical way of imagining the conundrum of self and

2 Although Heidegger does talk of Thinking (Denken) that belongs to or arises from being (Sein). See Heidegger (1954). 
other that seems to lie at the very nucleus of the phenomenological enquiry into being, particularly in relation to possession. It is insufficient to explain such distinctive articulations of self and other implicit in possession in terms of 'culture', since this relativises the theoretical force of these formulations, devolving them to the status of objects rather than instruments of thought (Das 1995, 33). To put this in perspective, should we say that the philosophical conclusions of Husserl, Merleau-Ponty, Heidegger and Levinas with regard to the question of being, and of self and other are culturally situated, and arise, to rephrase Boddy, in a cosmos where the boundaries between an individual and her environment are acknowledged to be impermeable, inflexibly drawn, or not negotiable'? The reversal of the 'anthropological gaze' toward the 'demystification', for example, “of 'universalist', 'objectified' categories of Western sociology [or anthropology, philosophy etc.]” (Das 1995, 33) raises several deeply problematic yet critical issues if we are ever to move beyond being 'culturally solipsistic' while legitimately formulating alternative theoretical frameworks derived from the philosophical speculations of 'other' cultures.

\section{Alterity: the possibility of being another?}

The foregoing discussion brings me to an examination of another, for the purposes of this paper, critical term: alterity - perhaps the very cornerstone upon which religion and religious experience is grounded. As Csordas (2004, 164) states: 'Alterity is the phenomenological kernel of religion. Insofar as alterity is part of the structure of being-in-the-world - an elementary structure of existence - religion is inevitable, perhaps even necessary.' But what does alterity mean, and how am I using the word? Alterity has most recently been employed in post-colonial studies to indicate the existence, and condition, of the colonised and culturally 'other'. 'Otherness' therefore pertains to the linguistic, political, epistemological, and imperial mechanisms through which the culturally and colonised 'other' is constructed. From an anthropological perspective alterity is understood 'as referring to political, racial, ethnic, gender, class, religious otherness - the otherness that is the occasion for identity politics, war, conflict, violence' (Csordas 2004, 173). Amongst these many divisive and colonising aspects of otherness, there is also the important sense in which it is used to describe the condition of women in both first and third world situations as being the 'other' of 
men. ${ }^{3}$ But as Arendt points out: 'alteritas or otherness belongs to everything not just to the marginalized [...] difference is our human condition.' Moreover, ““alterity" reconceived in terms of multiplicity opens the possibility for the community of plurality [...]' (Cutting-Gray 1993, 41). The re-conceptualisation of alterity as multiplicity brings us to a further philosophical differentiation of the term. Christopher Macann develops an extended and nuanced threefold understanding - an ontological alterity (human being-being), an ontic alterity (subject-object) and a reflective alterity (consciousness and what it is consciousness of) - that distinguishes difference from distinction:

Difference always presupposes a whole that is differentiated. Distinction begins with isolated entities that then have to be related. So distinction takes its start in a world that has already been differentiated to the point that the whole has been lost sight of and all we can see is analytically reducible objects.

(personal communication; see also Macann 2007) ${ }^{4}$

Following on from this, I use the term in a layered, stratified sense that carries traces of the meanings outlined above, but also applies a different sense. Since my case study involves an aspect of South Asian culture which speaking from a colonial context can be regarded as 'other', my use of alterity includes the meaning it has as describing the 'culturally other'. I also use it in the sense of women being 'other', as the event I will be recounting from the Central Himalayas reveals. The fact that women are viewed as 'other', is particularly relevant to the discussion of possession when we take into account the seemingly overwhelming preponderance of the participation of women in rituals of possession in the vast majority of scholarly materials collected from different cultures (see Bourguignon 2004, 557). As Bourguignon and others attempt to explain, women - because of their lesser status to men and the concomitant condition of emotional, financial, social, and domestic oppression - utilise the complex ritual, narrative, as well as somatic and psychological mechanisms of possession to regain and reinstate their voice through socially and religiously legitimate means. The embodied state of alterity expressed through the ritual processes of possession then becomes, in this explanatory model, a channel for symbolic action. The religious or spiritual views expounded by the women (or men) in such ritual contexts are in reality

3 See also Hannah Arendt's study of Rahel Varnhagen, a Jewish woman who presided over a premier intellectual salon in 18th century Berlin, as a dual issue of otherness; in Cutting-Gray 1993, 38.

4 Further, in Levinas' work and also in the work of Hegel, the 'other' becomes the foundational reference for the possibility of 'self-consciousness'. To be self-aware means being aware of the 'other'. Alterity may also refer to that which in a Judeo-Christian context is wholly other - a divine presence, the infinite, or God. 
not what they are being stated as (the presence of divine or malevolent beings); rather these are mostly 'unconscious' strategies adopted by socially deprived actors. Bourguignon's $(2004,558)$ view of possession as symbolic action, with its heavy bias toward 'etic' explanations, is problematic inasmuch as it endorses a particular view of the 'other' (both in the sense of culture and of gender) while propping up a set of values and possibilities germane to modernity.

And, finally, most critically, I use the word alterity to describe the possibility of multiplicity (and permeability) in the phenomenal world and the possibility of divine presence in human life. But there is a radical departure from the usual philosophical understanding of the 'other', whether human, non-human, or divine. In fact, I would like to bring in the notion of 'another', rather than 'other'. Ghassan Hage (2009), for example, talks about the anthropological gaze as being about the possibility of being another. This idea, he suggests, implies the idea of excess that is grounded in potentiality rather than actuality. Any given social situation or identity has the promise of being more than what it appears to be, is represented as or perceived to be. Actuality, on the other hand, is grounded on a notion of 'what is' or of stasis and 'predictability' rather than in a dialectic that can result in an unpredictable (re)configuration of 'what is'. Hage calls the ability to be another 'radical alterity'. Radical alterity thus moves beyond the chasm between self and other upon which much of anthropological, historical and philosophical thought is based. It is important here to acknowledge the powerful persuasiveness of 'actuality' as a pervasive perception of what is considered to be real. The 'real' as that which is limited, immovable, bounded. ${ }^{5}$ The 'real' as a commitment to fixity and petrifaction under the paradoxical guise of progress, change, and modernity - as the justification for cynically continuing to operate in the way 'things have always been'. The 'real' is based on what our senses tell us and on what the social conversations around us tell us. Not only do our senses and their filtration through social conversations tell us what is real but also what is true. There is a 'collapsing together', so to speak, between the real and the true in the world of actuality. Hage points out that the markers of this world are both fatalism and naturalness. In other words, the actual world is presented as though it is a given and naturally existing condition in which events take place in a predetermined and therefore fatalistic manner. And yet, it is only on the basis of the recognition of the existence of 'actuality' and of its limitation that something more can be felt, conceived and imagined. The recognition of the power of limitation inherent in pledging oneself to actuality, in fact, simultaneously transforms

5 I am using 'real' in contradistinction to Lacan's use of 'The Real' that denotes the unnameable, authentic, infinite, being or self that is prior to language and independent of our sensory experience. 
into the realisation of a deep 'misrecognition'. Only then can the world of potentiality and possibility be created and experienced.

Thus, for example, in Upanishadic and Vedantic thought neither divinity nor other sentient and non-sentient entities are fundamentally 'other' (anya). The perception of difference or 'otherness' rests on objects possessing name (nama) and form (rupa), but not on ontological difference. On the level of Being or Self (atman-Brahman), there is, in fact, no 'other'. Ultimately, all there is, is 'Self', 'Consciousness' or 'Being', although this cannot be directly apprehended through language, and is not based on a distinction between objects within the world. It is 'not this, not this' (neti neti). The philosopher Shankara, however, states that Brahman or 'It'

can be indirectly designated for example, by the word "I". The word "I" directly denotes my ego (ahamkara), but since the ego is a reflection of the true Self, as the mirror image is a reflection of the fact reflected in it, one can use the word "I" nonmetaphorically to indicate the Self. But all such usage presupposes [...] the operation of ignorance, a failure on our part to discriminate the true Self from the jiva, ego, or whatever.

(Potter 1981, 60)

Therefore, while on a purely phenomenological and linguistic level there is an 'I' and a 'you' and a 'world', on an ontological and experiential level these distinctions dissolve leaving no separation between me, you, and the world. In other words while our everyday experience and perception based on our senses (indriya) tell us that there are 'others', these are not as radically different and unreachable as some of the philosophical traditions outlined above would have us believe:

One has to recognize a difference in levels of understanding, between reality and appearance. On the highest level, on which awareness of reality [...] occurs, there is no possibility of difference. From the lower level, the level of appearance, myriad distinctions are of course apparent, but this is entirely the work of avidya or ignorance [...]. At the heart of our confusion is the notion, due to avidya, that my consciousness is different from yours or from anything else at all.

(ibid., 62, 70)

While this perspective may seem historically and culturally antiquated, being ascribed to ancient India, it is a perspective that is found, at least on a discursive level, amongst many members of India's contemporary population both rural and urban. As both a philosophical position and as 'popular' discourse it needs to be taken as seriously as the philosophical traditions of Descartes, Heidegger and others. In Vedantic thought alterity is reconceived as multiplicity, but this multiplicity encompasses more than the immediate arena of human relationships, more than the multiplicity of cultures and individual perspectives. In theory it covers all possible entities, and all past, present and future possibilities. It approaches Arendt's notion of a 'community of plurality' through the simultaneous acknowledgment of the reality of multiplicity on the one hand, and its dissipation, dis- 
solution and illusory nature on the other, through 'non-duality'. Can we state that this philosophical position also informs, to a large extent, the predominant cultural understanding of the relationship between self and other in the Indian context? This claim should not come as a surprise, since Cartesian thought, which has its roots in abstract and complex philosophical debate, also permeates the dominant structuring of the social and political world in the post-Enlightenment era. Modernity as an ideological discourse and institutional foundation itself is in many ways a product of the divisions created by Cartesian thought: mind-body, religious-secular, organic-mechanic, analytic-synthetic, subject-object and so on. And, while non-philosophers may not be aware of the intricacies of Descartes' and subsequent philosophers' thought, their ideas occupy an elemental, and yet largely unreflected place in the world of everyday transactions and discourse.

Pertinent for our understanding of these differently constituted parameters of selfhood, are also Piatigorsky's $(1985,217)$ observations on a phenomenology of Indian religion in which he discusses, among other categories, 'the structure of religious consciousness' which 'can be defined as a complex whole, the related elements of which produce in their totality a complete model of religious behaviour, i.e. of the religion'. Piatigorsky applies the idea of 'the structure of religious consciousness' to various aspects of Hindu religion, including that of the concept of god (deva) that 'implies a specific kind of differentiation fundamentally different from the concept of God (and from pagan gods) in Mosaic religion' (ibid.). The concept of ' a god' is particularly relevant for our conceptualisation of possession in the Indian context, since

[t]aken at a given time and in a given place [...] a god is present as an istadevata (chosen deity), that is, a phenomenon in which the idea of the god momentarily present coincides in time and space with that of his devotee and is merged with him in the context of a particular subjective religious situation. As in the case of atman-brahman, the subject and object of worship are not opposed to one another but seen as two instances of manifestations of the same entity.

(ibid., 219)

This notion of identity or equivalence between subject and object, particularly in the instance of worship and ritual, is crucial to how we view 'possessed bodies' in the Indian context. The body is the middle ground, so to speak, in which both the dual and the non-dual manifest, in which human and divine interchange, swap around, merge, become one, but also become two. The interactive, 'in-between space' is the space of ritual in which presence is urged and drawn out into existence but is never taken for granted.

Following on from this, I contend that non-duality is a framework within which to place our understanding of possession in the Indian cultural and religious situation. Non-duality is a context in which the question of self and other, 
of alterity, is addressed in a fundamentally distinct manner from how 'Western' situated philosophical ideas address the question. It may be counter-argued that the philosophical position of non-duality briefly outlined above is merely indicative of a single standpoint within several other divergent philosophical systems in India, and that the former represents an elite if not exclusive view that has little bearing on the so-called level of folk or popular religion and culture to which possession rituals belong. However, it can be asserted with good reason that the manner in which the question of multiplicity in the phenomenal world and diversity within the social universe is 'explained' on a popular, non-elite level, is through precisely the same philosophical discourse: the 'many' is the 'one'. ${ }^{6}$ Difference, while 'real' on the level of everyday transaction, is 'illusory' on a transcendental level. This transcendental level becomes immanent if the misrecognition of the reality of the ephemeral person-individual is acknowledged.

What this implies is the possibility of a multi-dimensional, porous, permeable, fluid identity, self, even 'no-self' or self as 'no-thing' that not only reinforces but also elicits a full engagement with the world. The notion of a 'decentred' or even non-existent self approaches the phenomenological and existentialist view of self and of being that is carved out against the background of nothing. However, the existentialist view of nothing and of self as 'no-thing' is accompanied by a fundamental mood of anxiety, fear, and dread, and an angst-filled, nihilistic response. This mood can be broadly described as a condition of alienation which itself can be likened to being 'ensorcelled' or 'diseased' in an ontological sense: 'Becoming "ensorcelled" is a slow process of [...] devolving toward an alien "otherness" [...]. All forms of objectification contribute to this process' (Handelman, Shulman 2004, 213f.). Thus we have somewhat overlapping conclusions regarding the nature of self or being. The responses to and scope of these conclusions, however, diverge and vary (see also Sax 2002, 9). The existential view overlays nothing with a particular pessimistic meaning: that life has no purpose as such (Sartre), but it also reinstates nothing as the ontological background for the creation of all possibility, and of something (Heidegger). The focus is primarily on

\footnotetext{
6 The matter of what constitutes folk or popular religion within Hinduism, both on a conceptual and ethnographic level, is one that has received considerable attention through the work of Sontheimer (2005) and Fuller (1992). Stereotypically, folk Hinduism has been considered as being devoid of the kind of metaphysical and philosophical reflection that signifies Brahmanical Hinduism. However, this is indeed questionable, as this view mirrors the prejudices 'elite' forms of religion might harbour toward 'non-elite-folk' forms of religion. It is important, though, to note the sheer corporality and immediate presence of gods or goddesses in folk religious ritual and practice, unlike in the Brahmanical situation in which deities may exist in a separate extra-terrestrial location (svarga) (Sontheimer 2005, 315).
} 
the being of human being, and on the possibility of inter-subjectivity as framed by social and political relationships between human individuals. In the Indian context, in contrast, the constructed nature of the social, phenomenal self is seen as the source of an existential condition of bondage which in turn gives rise to feelings of fear, anxiety, anger, greed, power, violence etc. because of a fundamental misrecognition involving the illusory, ephemeral nature of the bounded, therefore limited, individualised, egocentric self that is concerned with its own immediate survival (this can be extended to include community, religion, tradition, territory, nation). Freedom from these forms of constraint lies in the admission of the primordial misrecognition in which the 'deconstruction of the phenomenal self is only a necessary step toward coming to know the real Self, which is not to be confused with the phenomenal personality or ego' (Sax 2002, 15). Brahman, like Being (Dasein) in the phenomenological enquiry of Heidegger, is also nothing as it cannot be circumscribed through language nor identified through objects, and yet it is the non-existent ground from which something, i.e. the phenomenal world, arises. ${ }^{7}$ The Self or Brahman is thus not limited in any way by the conditions of the four-dimensional world consisting of the co-ordinates of space and time. Thus there is no need or indeed possibility to 'protect' or 'defend' 'It', as 'It' has no boundaries. This misrecognition or ignorance (avidya) applies not only to the being of human being, but equally to the being of all sentient and non-sentient entities. The re-conceptualising of alterity to encompass multiplicity, as Arendt suggests, is not confined to human inter-subjectivity, but to an ever-widening orbit in which both human and non-human, living and non-living participate. But even the condition of complete self-knowledge that Brahman represents is not - as pointed out earlier - a constant. This knowledge, to take the Shaiva Siddhanta view which both coincides with and diverges from the Advaita perspective, is fragile, tending toward rigidity and brittleness and, in fact, a loss of self-knowledge that is counteracted through a dynamic interactive process in which Shiva (as non-dual) unfreezes aspects of himself that have succumbed to closure, limitation, and a lack of movement (Handelman, Shulman 2004, 212). Ritual action involving the body, particularly in the form of dance (see below), is the movement through which divine knowledge and presence is re-created or 'unfrozen'.

The possibilities of 'self' explored above are intertwined in any discourse of possession, particularly in the South Asian context. Thus, for example, to return

7 Heidegger's notion of Being, like the concept of Brahman, is peculiarly disembodied. As Christopher Macann points out: 'Heidegger investigated the question of being from the standpoint of a Dasein that was never allowed to be its body. One has to bring Heidegger and Merleau-Ponty together to allow for an investigation of being from the standpoint of a human being whose being is defined in terms of its being a body' (personal communication). 
to Boddy's brief definition, she uses the term 'individual' in the sense that, as we have seen, is grounded in Western notions of person and self. Linked to this is the idea of 'permeability' and 'flexibility' when it comes to boundaries between individuals and their environment. The latter possibility is grounded in non-Western notions of self and of person that, at least in the Indian context, have no fixed, lasting reality. The hermeneutics of possession therefore uses a hybrid language, crisscrossing - perhaps unconsciously - between the notions of individuality and fixity which researchers themselves carry and 'blurred', fluid boundaries and identities encountered in the field. I argue in this essay that our understanding of possession and of alterity as divine intervention involves a mixing together of different voices, ideologies, and 'life-worlds' in a dynamic, 'swirling' conversation. These entangled, hybrid, perhaps fused, and yet oftentimes divergent views of self are a crucial component in arriving at a critical, and possibly radical new understanding of what we have been calling 'possession', and how we talk about it.

The discussion of 'modern' and 'pre-modern' notions of subjectivity outlines the framework in which I will present the following ethnographic case study of a Hindu deity in the Central Himalayas. Before presenting these materials, I found it necessary to first lay bare the categories and concepts that are inextricably tied up with the colonial and post-colonial enterprise of scholarship, particularly the scholarship dealing with South Asia. As Peter van der Veer, in his review of Asad's work, points out:

the project of modernization, which is crucial to the spread of colonial power over the world, provides new forms of language in which subjects understand themselves and their actions [...] it is almost impossible to escape these categories of western history, such as "public" and "private", "religion" or "history" when writing the history of other societies.

(van der Veer 1995, 366)

Much of what I am exploring then is my own attempt to unravel the taken-forgranted conceptual underpinnings and biases of the way I perceive the powerful experiences I have encountered during my fieldwork with regard to Goludev, the Central Himalayan 'God of Justice’ (nyay ka devta).

\section{Central Himalayan possessions}

Goludev is the principal deity (istadevata) of almost all 'high' and 'low' caste communities, including Thakur (Rajput), Brahman and Dalit, located in the northern Indian province of Kumaon, a mountainous region that borders on Nepal in the east and Tibet in the north, flanked by some of the highest peaks in the Indian 
Himalayas. There are several shrines and smaller temples of Goludev scattered over the region, but the deity's main temples are situated in Chittai (Almora dist.), Ghoda Khal (Nainital dist.), and Champavat (Pithoragarh dist.). The location of these temples is linked to Goludev's biography, with each temple being connected to different incidents in his life. For example, the temple in Champavat, which is the smallest of the three temples, is linked to Goludev's birthplace, and the capital of his father, King Jhal Rai. The temple in Ghoda Khal, where the incident described below involving the young woman embodying the Goddess takes place, is associated with Bhagoli Mehra, a woman devotee of Goludev who draws the deity to this location to deal with the abuse she is encountering from her in-laws.

The journey from Champavat to other locations traces a movement of the deity, driven by the pursuit of justice, across the region, which then gets established as the kingdom of Kumaon under his jurisdiction. Significantly, his powerful sense of justice derives from his own experience of injustice as a child. ${ }^{8}$ Goludev's devotees are able to solicit his intervention in matters of justice (a category used here to cover a wide range of life concerns) in two predominant ways. The first way of requesting his mediation is through the submission of written petitions (manauti) in his main temples mentioned above that are also described as 'courts of justice' (kaccheri). The second manner of soliciting his advice and intervention is through an oracular ritual called jagar (see Malik 2009; 2011; 2015; 2016).

The petitions can be written on official stamp paper but also on blank sheets. These are offered to the deity in his temples, where they are hung together with hundreds of brass bells that are gifted to the deity if the petitions are successfully dealt with. The petitioners' concerns are varied: conflicts over land-ownership and property, success in examinations, health, business deals, marriage, divorce, children, mental problems, addiction, enemies, lotteries, elections, success with job applications (see Agrawal 1992; Malik 2015; 2016). The second important manner, besides petitions, in which Goludev deals with matters of justice (and indeed healing) is through what may, in conventional terms, be described as an oracular trance ritual, but which I will refer to as a ritual of embodiment called jagar (see Malik 2011). Jagar means 'waking', 'staying awake', and is sometimes translated as 'night vigil'. The jagar can therefore be described as an intense ritual of 'awakening' for both deity and devotees (see Krengel 1999, 281).

8 For a synopsis of Goludev's biography, see Malik 2016. 
The jagar has two main actors: a singer or bard called the jagariya (literally 'awakener') and the person entering into a so-called trance who is called the dangariya (see Malik 2009). Both jagariya and dangariya, in contrast to the high-caste priests of the larger temples of Goludev, may often, though not always, belong to low-caste Dalit communities. The dangariya is, more importantly for the questions that will arise below regarding the young woman's embodiment as the Goddess, also called nacnevala (dancer). Like written petitions, the concerns of devotees during a jagar can vary, though often the presence of the deity is used to establish the hidden causes of illness, misfortune or injustice (see Krengel 1999; Leavitt 1997). ${ }^{9}$

\section{The woman who is goddess}

My case study focuses on a young woman who is 'spontaneously' possessed by the Goddess in the temple that was established through Bhagoli Mehra, the woman devotee of Goludev mentioned above. ${ }^{10}$ The young woman embodies the Goddess (Devi) during the Navaratra festival, the festival of nine nights, which celebrates the deeds of the Goddess ending with her slaughter of the buffalo-demon, Mahishasura, who has usurped control of the universe from the gods. By slaughtering the buffalo-demon, the Goddess is able to restore balance - dharma - in the world. This narrative dealing with the Goddess's warring deeds is first found in a Sanskrit work from the 6th Century CE called the Devi-Mahatmya (see Coburn 1991). It is subsequently narrated along with extensive instructions for the ritual propitiation of the Goddess in a 12th Century CE Sanskrit work called the Kalika-Purana (see van Kooij 1972). In addition, the story has almost universal occurrence across the Indian sub-continent in the form of narratives, and ritual enactments often involving animal sacrifice.

9 Jagars are most often performed in the environment of a devotee's home into which the singer and dancer are invited. Immediate family members, but also a wider public from the village participate as the audience.

10 While this incident happens outside the ritual framework of the jagar, it is not uncommon that a person may embody a deity within the sacred space of the temple. 


\subsection{The setting}

Several hundred families and pilgrims are visiting the temple and performing puja (worship) in front of the shrine of Goludev. Diagonally opposite the shrine, in front of a set of three-pronged trees, is a dhuni (sacred fire) that is smouldering with large logs, and halves of dry coconuts that have been split open for pilgrims to take home the tender kernel as prasad (consecrated food). A few metres behind the dhuni, along the outer wall of the temple, there is a small newly erected room with pictures of Rama, Sita, Lakshmana and Hanuman. Inside the room, whose doors are wide open, the uncle of the priest of the Goludev temple sits reciting the story of Rama from the Ramcaritmanas. ${ }^{11}$ The recitation continues uninterruptedly during the day over the entire 9-10 days of the Navaratra festival. Pilgrims visit the priest's uncle, who is himself a priest of the temple of the goddess in another village, for blessings. A family performs kanya puja with a group of young girls. ${ }^{12}$ It is perhaps the third or fifth day, perhaps even later into the festival. It is late morning, approaching noon.

\subsection{The incident}

Suddenly there is a young woman, in her mid-twenties, who arrives at the dhuni. She has a large, scarlet rhododendron flower in her mouth. She begins to circle the fire. People milling around move away to give her room, forming a circle of on-lookers. The elderly drummer who is sitting with his back to the wall of the small room beats his drum; there is a distinctive but somewhat weak rhythm. The young woman begins to dance to the rhythm, all the while circling the fire. At one point she trips over one of the logs and falls badly on her side, almost into the fire. A middle-aged woman - her mother perhaps - tries to help her up. She continues around the fire one more time, then she drags a large log that is partially burning to the edge of the temple floor to the left of the drummer and the small room. She is handing out coconut halves to pilgrims who come up to her to accept the prasad. 'Who is this woman?' I ask people standing near me. 'It is Devi, the Goddess', they answer.

The young woman moves away after a short while from where she is sitting and positions herself in an area about two metres in front of the main shrine.

11 This is a retelling of Ramayana in Avadhi-Hindi by the poet Tulsidas: $16^{\text {th }}$ Century CE.

12 This involves the worship, feeding and giving of gifts to seven pre-pubescent girls who are treated as manifestations of the Goddess (Shakti). 
There are crowds of people either sitting or bending under the low-lying roof of the shrine. A priest sits inside the shrine and another stands in front reciting in Sanskrit, conducting puja for groups of families clustered around the narrow opening of the small shrine. There is a lot of bustle and noise from the people talking, the recitation, the ringing of bells. Amidst the loud recitation and ringing of bells, the young woman speaks in a clear, strident voice that is audible above all the clamour. She asks a straightforward question that initially flusters the priest: 'Who are you worshipping? Do you know who you are worshipping?' The priest stops his recitation and begins to answer hesitantly that it (i.e. the puja) is for Goludev. But she continues asking questions in an even louder, more penetrating voice: 'For whom are you performing puja? If you don't even know for whom you are doing puja, then what exactly is it that you are doing? You should perform puja for each individual family in a clear manner, not collectively for everyone!' After a short time, the young woman moves from her position near the shrine to the room in which the elderly priest is reciting episodes from the Ramayana. She begins to take slow steps around the priest, sprinkling consecrated water over the white cap he is wearing. The priest does not look up or stop his recitation. She sits down in front of the priest, swaying slightly to the rhythm of his recitation. Before I enter the small room, I have a brief conversation with the priest of the temple. He asks me whether I have had darshan ('seeing', audience) [of the young woman]? I answer in the affirmative, but he continues in a somewhat derisive manner that he's not sure about this darshan - he doesn't quite understand what's going on here... it could be anything, he can't say. I ask him: 'Is it Devi?' He says one can't say for sure...

\subsection{The conversation}

After a while the young woman stands up and begins to have a conversation with her family members:

I'll tell you after six months. No one has asked me yet! If no one has asked me what should I say? No one has come here. People from the family should come here. If anyone dies in your family, if someone's head gets cut off, it's not my responsibility... even if I come into anyone's body... if anything happens... if anyone gets killed. I told them to phone up and call people [from the village]. Now I'm going to fulfil your wishes and everyone else's in the temple [but not those who haven't come here]. I came to the temple to tell you this. This temple has [only] one rule, which is, if they get money they will perform puja, otherwise they won't. [i.e. they are only interested in money]. If they get money they will perform puja. This drummer only plays if he gets money in his pocket. The temple stays open for 24 hours and so should the drummer [be here and play]... this drummer's desires will never be fulfilled... his stomach will never be satisfied... I'm telling you this... If anything happens to anyone else, I'm not responsible. I'm responsible for the family who came with me. 


\title{
5 The swirl of worlds
}

\begin{abstract}
Whereas possessed bodies were likely to be approached as anachronistic bodies influenced by beliefs that the scholar did not hold, I have argued for an approach that both acknowledges that the possessed body is powerful and that scholarly studies of possession are produced by a desire to be in proximity to alterity, which is often masked as an intellectual desire to explain the possession...

Mary Keller $(2002,103)$
\end{abstract}

How do we frame, represent or understand this 'incident'? Can we claim that this is indeed divine embodiment? Or is this the only way an otherwise socially oppressed young woman can articulate her 'voice'?

Let us look at what is she saying and doing. Her words seem all along to be unflinchingly critical. There is a quality of straightforwardness to them as she speaks both to the temple's priests but also to her own family. Her comments about the temple and its custodians are bitingly precise, uncovering their corrupted and lax operation of what, according to her, ought to be a pristine location of worship and service. Her speech toward her family is reproachful and threatening, pointing out that they and others have not granted her the attention she deserves: But then she also turns to blessing the family who has gathered around her, while making it clear that people from the village who did not heed her call to come to the temple on that day would not be blessed. Moreover, her speech has the nature of a foreshadowing, of a prophecy; it is even oracle-like. She expresses a purposefulness and foreknowledge of her actions. At the same time there is a cryptic quality to what she is saying, a sense of some purpose that is still hidden from the view of her family and onlookers: a purpose to her presence at the temple that will be revealed only in time. These pronouncements and their implicit but simultaneous meanings as being threatening, revealing, hidden, critical, reproachful, benevolent, and foreknowing taken together create the conditions for authority, power, and sovereignty that she, as Goddess, exemplifies. Her pronouncements also make it clear that the Goddess is aware of her own capacity to 'occupy' a body for the purposes of such a visitation. By virtue of this self-conscious statement, the Goddess is also making a vital distinction between herself and the body she 'instrumentalises'. The Goddess' pronouncements importantly represent a prophetic voice. Prophetic not just in the sense that it alludes to something in the future being revealed or a prefiguration of present events, but also in that it represents a voice from within the religious institution itself that is intensely critical of the corrosion that has crept into the structures of that very institution. The Goddess' statements are both dissenting and rejuvenating at the same time, with the explicit rationale of restoring the original purpose - indeed dharma - of the temple and its functionaries. She mirrors the objective of the Goddess in texts such the Devi-Mahatmya and Kalika-Purana toward the restitution of a cosmic 
order that has degenerated on account of the entropy-creating usurpation of power in the world through demonic forces. In addition to the force of her speech, the Goddess' movements with regard to her own body but also through different spaces of the temple compound are significant. Her actions are designated as nacna (dancing), which is also used to describe the actions of a person appointed to embody a deity during a jagar. Her movement across different spaces of the temple involves a circular motion around the sacred fire and the priest who is reciting the Ramayana. But it also involves her sitting directly opposite the deity's image in front of his shrine, and, after she has circled him, sitting opposite the priest. The circular movement around the fire, and the priest, are indicative of the clockwise circumambulatory steps (pradaksina) that pilgrims or devotees undertake while paying their homage to a sacred object or person as the case may be. While the sacred fire is an obvious choice in terms of importance in the geography of the temple, the reason for her election to circumambulate the priest is not immediately apparent. This seems to be connected to the strong, yet invisible' charismatic attraction of the priest who single-mindedly and passionately pursues his uninterrupted chanting of the story of Rama. Throughout this event, the priest does not waiver in his concentration or allow himself to be distracted, even though the young woman walks closely around him, laying her hand on his head as a form of blessing, and even sprinkling consecrated water over him. Later she sits down facing him in close proximity, just as she has done in front of the main image of the deity, although there the crowds of devotees keep her from getting as close as she does to the priest. The Goddess' presence is thus made known through a series of significant utterances but also bodily movements identified as dance resulting from her circling the sacred fire and the priest.

Returning to the questions put at the beginning of this section: How do we explain what is going on here? Is it divine embodiment? Or is the young woman expressing her 'voice'? In other words, does it involve the Goddess' agency or the woman's? I consider it worthwhile at this point to introduce some ideas put forth by Mary Keller (2002) who uses Asad's work on the 'Genealogies of Religion' to critically appraise the question of possession, agency, and women. There are several important issues that Keller raises, particularly with respect to the notion of agency that in post-colonial scholarship is 'cheerfully' attributed to third-world subjects, in particular to the 'rediscovery' of women as agents. Keller (2002, 62f.), while emphasising the need to historicise scholarly discourse in terms of culture and power - particularly with regard to the concept of 'religion' - signals the peculiarity of the attribution of 'voice', that is both withheld and granted by the same instance of authority, namely, 'imperialism' (in the colonial context) and 'global capitalism' (in the contemporary political context). Keller, following the work of Asad, suggests that the notion of a bounded or 'buffered' person only arose in 
the post-Enlightenment epoch in which several radical divisions were made, the most significant being perhaps the division between the state and the church, but also, through the work of Descartes, as pointed out previously, the division between mind and body. Within these far-reaching alterations to the view of society and human beings' place in the world, the foundations for the idea of an autonomous individual or rather agent were also laid. Asad argues that the idea of an autonomous individual in charge of her/his destiny replaces the 'pre-modern' understanding of person and of body that was not as an autonomous agent but as an instrument through which divine power (disciplina) could flow. He states that the modern, privatised notion of religion specifically, and modernity in general, 'extinguishes various possibilities', one of them being perhaps a notion of the religious body and 'human subjectivity to be at the disposal of God's will' (ibid., 56). Furthermore, he argues that agent does not equal subject ('where the former is the principle of effectivity and the latter of consciousness'); they 'do not belong to the same theoretical universe' (ibid., 63f.). Keller develops this idea in a new framework for understanding possession, particularly possession involving women, in her notion of instrumental agency. Instrumental agency, in distinction to the idea of autonomous agency, suggests the possibility of agency not based on the idea of a bounded, discreet individual, but rather on that of the body as a field upon which various socio-biological forces converge, and that is open to the work of divine power: 'The body that navigates these systems is understood to be instrumental rather than self-constituting; it is tempered by social and biological forces' (ibid.). Consequently, Keller argues that '[p]ossession is not a symbol for action; it is action or disciplina that produces knowledge in the bodies of the possessed. The possessed body is an instrumental agency - a body marked by its activity'. Simultaneously, Keller suggests that instrumental agency, rather than being a matter of individual volition and intentionality, is created through the agreement of a social group or community. Here again, agency shifts from being located in the private, and perhaps even isolated realm of the individuated self, to that of the shared space of the public realm. The critical issue then of how we view and approach the phenomenon of 'possession' rests on our conceptualisation of what constitutes agency and person or rather 'subject'. As I have already pointed out, in the Indian context, the reality of the social subject is deconstructed because it is based on a false apprehension of the concreteness of a bounded, individualised self.

I maintain that it is valuable to use Keller's idea of instrumental agency as being created through a set of 'social and biological forces' by taking this further to include, in a deeply constitutive manner, different voices making up a conversation that embraces divergent pronouncements: those that affirm the presence of the Goddess, those that are sceptical or doubtful of it, and even those that 
downright deny its possibility. For example, the young woman's family and several visitors to the temple affirm the presence of the Goddess; the main priest of the temple occupies an ambivalent or sceptical position. Scholars, however, are unsure, since to agree with the devotees' perspective would be tantamount to surrendering scholarly distance and objectivity. But to completely deny the possibility of the 'reality' of what is happening would amount to too much objectivity, and the extinguishing, as Asad puts it, of 'various possibilities'. All these perspectives - those of the young woman's family, the devotees, the drummer, the priest, the Goddess, the scholars - constitute the 'reality' of the Goddess' embodiment-presence. Her embodiment is made up, so to speak, of a 'swirl of worlds': each given by a different set of concerns, but none, however, being necessarily privileged over another.

\section{The play of conversation}

The notion of a 'swirl of worlds' is inspired by Hans-Georg Gadamer's exposition of 'Dialogue' and 'Conversation'. Gadamer uses the metaphor of conversation to describe how we can enter into a dialogue that leads to understanding (Verstehen).

[It] is a process of two people understanding each other. Thus it is a characteristic of every true conversation that each opens himself to the other person, truly accepts his point of view as worthy of consideration and gets inside the other to such an extent that he understands not a particular individual, but what he says. The thing that has to be grasped is the objective rightness or otherwise of his opinion, so that they can agree with each other on a subject.

(Gadamer 1979, 347)

Gadamer maintains that knowledge is not fixed or static but that it arises out of a dialogic process of interaction. This dialogic process requires each 'speaker' or 'participant' to both acknowledge and 'unconceal', so to speak, their inherent prejudices or 'horizons' ${ }^{13}$ Without engaging in this process of revealing or 'unconcealment' of prejudices, there can be no fruitful dialogue or understanding. While Gadamer $(2004,361)$ stresses the importance of texts and their interaction within a history of interpretation, his idea of conversation is particularly crucial because it suggests the aural and spoken nature of dialogue and therefore

13 See also Smith, M. K. (2001). I prefer to use the word 'concern' rather than prejudice to indicate the issues or questions speakers are dealing with in their lives that they then bring to a conversation. 
'emergent' nature of knowledge. Gadamer's idea of conversation - like his notion of play (ibid., 104f.) - can be likened to a medial plane in which the subjectivity of the speakers (or players as the case may be) is not in the foreground. It is the conversation (or game) that is in the foreground, having an existence that is almost independent of the speakers; the speakers' subjectivity is held in abeyance, much like the subjectivity of a possessed person. The speakers, in fact, enter and explore the emerging terrain of the conversation that unfolds as they speak. This is quite distinct, for example, from a discussion or debate that involves one speaker convincing the other speaker through argument or persuasion of the validity of their point of view. A dialogue, on the other hand, involves a willingness to be open such that third possibilities emerge from the conversation that may or may not have the quality of a conclusion. In fact, the 'end' of a conversation may be 'inconclusive': the point being one of revealing or 'unconcealing' a series of insights or questions that the theme of the conversation calls upon or draws out from itself. Following on from Gadamer's notion of a conversation, I elucidate a 'swirl of worlds' as follows.

Individual human beings or communities represent 'points of view' or horizons (to put it in Gadamer's terms) that are constituted by inherent and often unexamined interests or concerns that determine the constraints or limitations of any given horizon. Each horizon represents a world that is constituted by ideas (language) and actions (practices). In encountering a phenomenon like 'possession' we are confronted by a convergence of points-of-view or horizons, each carrying its own set of concerns. Assuming that the body in possession is played upon by 'social and biological forces', that are themselves constituted by a chorus of voices, the 'reality' of possession is made up of a set of hybrid discourses and practices consisting of academic and non-academic ideologies concerning self, body, power, agency and so forth together with academic practices (fieldwork) and non-academic practices (ritual). I am describing this as a swirl because of the shifting, indeterminate, and fluid nature of the interactions between these horizons, which, like spoken conversation, is constantly moving or changing, is sometimes fragmented like utterances, and is both ephemeral and unpredictable. Moreover, the notion of a swirl also suggests an interplay of voices that coalesces into an unconscious eddy that is not always self-reflective in the sense Gadamer suggests of 'unconcealing' hidden prejudices and given, 'always-already' ways of perceiving.

The scholar's perspective is given by a set of concerns that are philosophically grounded in the binary categories of modernity, some of which I mentioned earlier (private-public, religious-secular, mind-body, human-divine, subjectobject etc.). The woman's family's and the devotees' concerns, on the other hand, are certainly not given by this set of concerns. There is no primary philosophical 
concern with the division between the religious and secular or mind and body or human and divine; rather it is about 'seeing' the Goddess and gaining her grace and blessings for everyday matters. The main priest's perspective is given by a concern to maintain the manner in which he runs and administers the temple. It is not beneficial for him to have a young woman (or Goddess for that matter), publicly proclaim that the temple is a purely financial enterprise not seriously interested in being what a temple ought to be: a place of service, worship, and refuge for devotees.

Gadamer also argues that dialogue is about suspending the notion that any one perspective is more privileged (or more 'right') than another. Each horizon is equal inasmuch as it simply represents a particular horizon and nothing more. The critical point is that scholarship, particularly the scholarship on possession, attempts to 'escape' this swirl of (equal) worlds by assuming an 'objective' position. By participating in a secular, rational, scientific discourse, scholarship is, in fact, that construction of knowledge which attempts to put an end to the swirling by claiming it occupies more than just the status of an interpretation (in Gadamer's sense): that it is elevated to the position of scientific truth. By presenting itself in this manner it precludes us from seeing the multiple potentials inherent in different situations. But if we are to take the idea of dialogue seriously, then we must consider that scholarship itself is but one perspective within a 'swirl' of perspectives, interpretations or points-of-view. The point of the foregoing exploration is to make Gadamer's notion of dialogue applicable to our understanding of possession: a dialogue, in its most open form, can lead to the formulation of something that is beyond the initiatory statements of each speaker, and the horizons of what they initially know. Thus can we - as scholars - imagine an emergent and continuously expanding context which acknowledges a world in which we can be another?

\section{Possession as radical alterity}

I began this paper by saying that I would examine the possibility of alterity in the context of what is commonly called 'possession'. 'Alterity' as the possibility of the participation and intervention of the 'divine other' in human life, I have indicated, exists because of, and through a social conversation involving several voices and perspectives belonging both to the scholar and also devotees. I will conclude my presentation of materials from the Central Himalayas by some further remarks about 'possession', and about 'alterity' in the context of 'possession'. First, I would like to point out again that there is a steady pre- 
occupation, indeed almost fixation, with possession within several scholarly disciplines including anthropology, religious studies, sociology, linguistics, and medical disciplines. ${ }^{14}$ Both the desire to study possession and to explain it within frameworks that objectify it and are, in fact, experientially disengaged from it, I am arguing, stem from the challenge that possession poses to the dominant view that religion itself is separate from the public domain permeated by the secular, being rooted in the private domain of individual belief. But more than that, possession occupies one of the significant interstices of the modern age by transgressing and transcending binary categories with which modernity so dearly identifies itself. Modernity crystallises through a series of acts involving critical distancing: the individual from community, community from cosmos, culture from nature, equality from hierarchy, mind from body, and so on. These acts of distancing, furthermore, necessarily result in sets of binary, oppositional categories since modernity itself is predicated and defined on the fundamental distancing between the modern-innovative-new and ancient-traditional-old. We cannot know whether we are the 'moderni' unless we can contrast ourselves with that which we define as 'antiqui' (see Benavides 1998). The discursive category of modernity therefore must continuously create, and, in its political manifestations also intentionally perpetuate the existence of antagonistic dualities without which it loses legitimacy and force as an intellectual and political ideology. To continue along the lines mentioned previously, to be modern then is to both live and fervently believe in a society that values and, indeed, sustains divisions between public-private, human-divine, human-nonhuman-animal, secularreligious, individual-community, mind-body, and last but not least, bounded/ buffered self-porous/permeable self. While these dichotomous categories may seem neutral on paper, in practice they are far from impartial. Thus these oppositional categories involve a suppression in many instances of one of the pairings: the secular is clearly valorised over the religious, which may continue to exist, but only in the private sphere; humans are valorised over non-humans, especially animals, such that their survival can take place at the cost of the extinction of several thousand other species; the mental (mind) is valued over the biological (body) that it can presumably control, understand and analyse; individuals are given priority over the community in their quest for personal success and so on. It is to live in a political state that administers fixed categories of social identity in which excess is undermined and even denied. Moreover, individuals are driven by

14 As Boddy $(1994,407)$ notes: 'In contrast to anthropological accounts of the body or of time, spirit possession has [...] rarely missed a theoretical beat [...] the subject is thematic for the discipline as a whole in its confrontation with the Other, continuously affirming our identity as anthropologists.' 
an inner capacity to shape and manage their lives. Responsibility and cause are redirected almost totally in all possible domains - psychological, legal, social, financial, educational - to the individual or to extensions of the individual such as parents, siblings, peer groups. There is little recourse in the context of modernity to invoke forces or powers that lie beyond or even hidden within individuals' capabilities when it comes to the explanation of their actions. ${ }^{15}$

Possession, however, challenges these precise yet value-laden categorisations that lie at the source of modernity and its expression in the modern secular, nation state, and therefore there is a necessity to explain possession through reductionist categories. Possession is somehow that very 'vestige' of the past (the 'pre' or 'non' modern and traditional) - like its larger problematic counterpart religion - which shocks, amazes, and perhaps even embarrasses us in its continued, even thriving, survival within the realms of the scientific, technological, and rational. To allow possession to represent what it is, that is, the possibility of a multi-dimensional self in which self and other are identified through 'equivalence, enmeshing, and continuity' while operating in a public rather than private ritual domain, and the possibility of alterity in the sense of divine 'intervention' as such (whether in the public or private domain), is to question the foundations of a modern secular state built on the notion of the bounded, separate individual who is in complete control of her/his life and destiny. Possession, therefore, in a fundamentally distinctive manner forces us to rethink modern notions of agency and subjectivity. As the possibility of quite literally being another, possession thus represents the tangible prospect of a 'radical alterity' which goes beyond even its social, secular meaning. In view of the somewhat uncertain status of the ideological arrow of modernity and of progress in terms of the ecological and political disasters we are encountering today, divine embodiment represents one possibility of an alternative understanding of 'self', and of other ways of being for human beings, that we can take seriously if we are to authentically explore new possibilities for the future of being human.

15 The idea of a subjectivity that is not solely rooted in 'conscious', personal volition, is, of course, close to the experience of many artists, writers and creative individuals including scholars and scientists. Although creative insight may be often experienced as spontaneous, 'unexplained' or even 'channelled', this fact rarely enters scholarly discourse, as the latter has to do with the very opposite of 'insight' and spontaneity, namely reason, logic, argument, and rational thought. 


\section{References}

Agrawal, C. M. 1992. Golu Devata: The God of Justice of Kumaon Himalayas. Almora: South Asia Books.

Asad, Talal. 1993. Genealogies of Religion. Baltimore: John Hopkins University Press

Arendt, Hannah. 1958. The Human Condition. Chicago: University of Chicago Press.

Arendt, Hannah. 1958/1974. Rahel Vernhagen: The Life of a Jewess. Trans. R. Winston, C. Winston. New York: Harcourt Brace Jovanovich.

Benavides, Gustavo. 1998. 'Modernity.' In Critical Terms for Religious Studies, ed. M. C. Taylor, Chicago: University of Chicago Press. 186-204.

Boddy, Janice. 1994. 'Spirit Possession Revisited: Beyond Instrumentality', Annual Review of Anthropology 23. Annual Reviews. 407-34.

Bourguignon, Erika. 2004. 'Suffering and Healing, Subordination and Power: Women and Possession Trance', Ethos 32(4). American Anthropological Association. 557-74.

Coburn, Thomas B. 1991. Encountering the Goddess: a Translation of the Devi-Mahatmaya and a Study of its Interpretation. New York: Sri Satguru Publications.

Csordas, Thomas J. 2004. 'Asymptote of the Ineffable: Embodiment, Alterity, and the Theory of Religion', Current Anthropology 45(2). 163-85.

Cutting-Gray, Joanne. 1993. 'Hannah Arendt, Feminism, and the Politics of Alterity: "What Will We Lose If We Win?"', Hypatia 8(1). 35-54.

Das, Veena. 1995. Critical Events: An Anthropological Perspective on Contemporary India. Delhi: Oxford University Press.

Fuller, Christopher J. 1992. The Camphor Flame: Popular Hinduism and Society in India. Princeton: Princeton University Press.

Gadamer, Hans-Georg. 1979. Truth and Method. London: Sheed \& Ward.

Handelman, Don; Shulman, David. 2004. Siva in the Forest of Pines: An Essay on Sorcery and Self-Knowledge. Delhi: Oxford University Press.

Hage, Ghassan. 2009. Anthropology and the Passion for the Political. Inaugural Distinguished Lecture for the Australian Anthropological Society.

Heidegger, Martin. 1954. Was heisst Denken? Tuebingen: Max Niemeyer Verlag.

Heidegger, Martin. 1962. Being and Time. London: Blackwell.

Keller, Mary. 2002. The Hammer and the Flute: Women, Power and Spirit Possession. Baltimore: Johns Hopkins University Press.

Krengel, Monika. 1999. 'Spirit Possession in the Central Himalayas.' In La Possession en Asie du sud: Parole, Corps, Territoire, eds. J. Assayag, G. Tarabout, Paris: Éditions de l'École des Hautes Études en Sciences Sociales. 265-88.

Leavitt, John (ed.). 1997. Poetry and Prophecy: The Anthropology of Inspiration. Ann Arbor: University of Michigan Press.

Macann, Christopher. 2007. Being and Becoming: A Genetic Interpretation of the Being of Human Being. Part I: General Metaphysics. London: Online Originals.

Malik, Aditya. 2009. 'Dancing the body of God: Rituals of embodiment from the Central Himalayas', SITES: A Journal of Social Anthropology and Cultural Studies 6(1). 80-96.

Malik, Aditya. 2011. 'Is Possession Really Possible? Towards a Hermeneutics of Transformative Embodiment in South Asia.' In Health and Religious Rituals in South Asia: Disease, Possession and Healing, ed. F. Ferrari, London: Routledge. 17-32. 
Malik, Aditya. 2015. 'The darbar of Goludev: Possession, Petitions and Modernity.' In The Law of Possession: Ritual, Healing, and the Secular State, eds. W. Sax, H. Basu, New York: Oxford University Press. 193-225.

Malik, Aditya. 2016. Tales of Justice and Rituals of Divine Embodiment: Oral Narratives from the Central Himalayas. New York: Oxford University Press.

Piatigorsky, A. 1985. 'Some Phenomenological Observations on the Study of Indian Religion.' In Indian Religion, eds. R. Burghart, A. Cantlie, London: Curzon Press. 208-58.

Potter, Karl H. (ed.). 1981. Advaita Vedanta up to Samkara and his Pupils. Delhi: Motilal Banarsidass.

Sax, William. 2002. Dancing the Self: Personhood and Performance in the Pandav Lila of Garhwal. New York: Oxford University Press.

Smith, Frederick. 2011. 'Possession in Theory and Practice.' In Health and Religious Rituals in South Asia: Disease, Possession and Healing, ed. F. Ferrari, London: Routledge. 3-16.

Smith, M. K. 2001. 'Dialogue and conversation', The Encyclopaedia of Informal Education.

Sontheimer, Günther-Dietz. 1976. Biroba, Mhaskoba und Khandoba: Ursprung, Geschichte und Umwelt von pastoralen Gottheiten in Maharashtra. Wiesbaden: Franz Steiner Verlag.

Sontheimer, Günther-Dietz. 2005. 'Hinduism: The Five Components and their Interaction.' In Hinduism Reconsidered, eds. G. D. Sontheimer, H. Kulke, Delhi: Manohar Publishers and Distributors. 305-24.

Van Kooij, K. R. 1972. Worship of the Goddess according to the Kalikapurana. Leiden: E.J. Brill. Van der Veer, Peter. 1995. 'The Modernity of Religion', Social History 20(3). 365-71.

Winquist, Charles E. 1998. 'Person.' In Critical Terms for Religious Studies, ed. M. C. Taylor, Chicago: University of Chicago Press. 225-38. 